\title{
A Platform for Difficulty Assessment and Recommendation of Hiking Trails
}

\author{
Jean-Paul Calbimonte ${ }^{(凶)}$, Simon Martin, Davide Calvaresi, \\ and Alexandre Cotting \\ Institute of Information Systems, University of Applied Sciences \\ and Arts Western Switzerland (HES-SO), Sierre, Switzerland \\ \{jean-paul.calbimonte, simon.martin, davide.calvaresi, \\ alexandre. cotting\}@ @evs.ch
}

\begin{abstract}
In recent years, the popularity of hiking has steadily increased across different segments of the population. Although there is considerable evidence of the benefits for hikers regarding physical and mental health, the inherent risks of these outdoor activities cannot be underestimated. Accident prevention and an increase of awareness about possible risks are necessary to minimize hiking and pedestrian tourism's negative consequences. In most hiking information maps and interactive applications, there is usually not enough information about difficulty points or the granularity level required to provide tailored recommendations to hikers with physical or psychological limitations. In this paper, we present Syris, a geo-information system for hiking itineraries that incorporates Points-OfDifficulty to assess the level of effort, technique, and risk of hiking trails. The system allows users to filter itineraries and obtain recommendations based on the assessment of difficulty following a well-established methodology. The system has been implemented, deployed and tested with real data in the region of Val d'Anniviers in Switzerland, and is openly available to enable further developments and refinement.
\end{abstract}

Keywords: Hiking tourism $\cdot$ Difficulty assessment $\cdot$ eTourism systems $\cdot$ Semantic web

\section{Introduction}

Pedestrian tourism has recently experienced increased interest, paving the way for the emergence of (online) services and products for hiking and outdoor activities $[3,9]$. Nowadays, the availability of mountain paths and hiking trails reaches a wide range of population segments, from novice to expert users. The heterogeneity of the potential hiker profiles leads to several challenges, especially regarding safety and risk concerns, which have not been fully addressed by existing information platforms and applications. Indeed, in most mountain tourist destinations, there is only superficial information about trail difficulty and risks. Moreover, it is often not standardized nor reflecting specific elements that can drastically affect the overall hiking experience. 
In this paper, we describe the design, implementation, and deployment of Syris, a comprehensive platform for management and recommendation of pedestrian tourism trails, including the assessment of difficulties and risks. The design of Syris follows a methodology and data model for describing and representing points of difficulty, according to well-defined criteria [4]. Moreover, it includes visualization and filtering functionalities, aiming at providing tailored recommendations for users according to their physical skills and preferences. Furthermore, the platform includes a mechanism for data acquisition of pointsof-difficulty through a mobile application, leveraging knowledge, and experience from expert hikers on-the-ground. Finally, Syris has been deployed ${ }^{1}$ and tested in the mountain region of Val d'Anniviers in Switzerland, including real data on more than 70 pedestrian tourism trails of different characteristics, in collaboration with local tourism offices.

The remainder of the paper is structured as follows. We present an overview of the system in Sect. 2. The data model is presented in Sect. 3. Specific details about data acquisition, visualization, filtering, and deployment, are presented in Sect. 4, 5, 6, and 7 respectively. Section 9 provides a discussion about potential future developments based on Syris and finally, Sect. 10 concludes the paper.

\section{Syris Overview and Architecture}

Beyond existing systems in the market, Syris has been conceived as a prototype that integrates both geographical aspects of hiking trails and risk and difficulty information needs. To do so, Syris relies on a well-defined model for both hiking trails and their difficulties, and user profile models, as described in a previous work [4]. This model considers the complexities due to the subjectivity of difficulty information, related to the perception of risk from heterogeneous users. We have gathered evidence in previous works, through questionnaires and workshops with key actors in the Swiss tourism sector [5], that difficulty and risk assessment information is repeatedly demanded by end-users and tourism providers.

The Syris platform demonstrates the use of difficulty and risk information, as explained in Sect. 3, reflected in a user-friendly search and visualization interface (Fig. 1). This interface is complemented with recommendations of hiking trails matching user profiles, i.e., according to the physical condition and risk perception of users.

The main functionalities of the Syris Web application can be summarized as follows:

- Geographic visualization: depiction of hiking trails projected over Web mapping overlays. For the purpose of the prototype, the pedestrian routes are limited to the region of Anniviers in Switzerland. The map includes the usual features, including zoom + drag, the possibility of switching the map overlay (OpenStreetMap, OpenTopoMap, and SwissTopo), and clustering of routes according to zoom position.

\footnotetext{
${ }^{1}$ The prototype is publicly available at: http://syris.iigweb.hevs.ch/.
} 


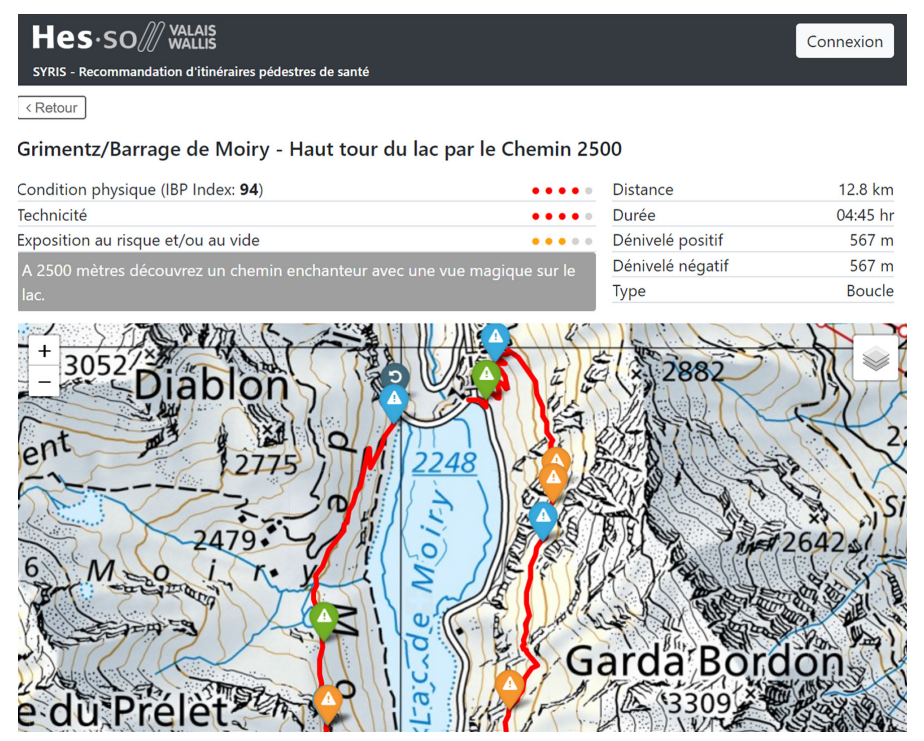

Fig. 1. Syris overview. Main interface displaying a particular pedestrian route along with its details and points of difficulty.

- Route filtering: pedestrian routes can be filtered according to by ability (effort, technique, and risk), for single users or groups. Route icons are color-marked according to the physical, technical, or psychological difficulty. Clickable icons display brief information about the routes and allow to display further details. A list of routes is presented along with the map, which changes according to the map's routes.

- Health profile: registered users can save their profiles, including their physical condition (effort skills), technique, and risk perception. These parameters are obtained by filling a version of the Baecke questionnaire [1].

- Customized list of routes: users may add selected routes to a list, display them, and add feedback to them. Tourist Offices may provide additional advice on specific itineraries. Custom filters can also be saved and associated with a list of routes.

- Visualization of points of difficulty: specific difficulty points are highlighted in the map visualization. The itinerary's start and endpoints are also highlighted, as well as additional information about the difficulty and other route attributes. Routes and points of difficulty can be exported as GPX and KML.

- Authentication and administration: includes registration, login, and basic access control. The administration interfaces also allow CRUD operations on routes, PODs, users, roles, outputs, feedback, health profile, links to other applications (e.g., OutdoorActive).

The architecture of the Syris platform is depicted in Fig. 2. We chose to use a geospatial database to store routes and difficulty points. A PostgreSQL database 
with PostGIS extensions has been used in combination with the Python Django Framework for the dynamic processing of itineraries on maps. The following technologies have been included in the prototype implementation:

- PostgreSQL for the attributive data (users, profiles, route details, etc.)

- PostGIS for geospatial data (points of difficulty, routes, spatial operations).

- Django and Python for Web development and Web services.

- Leaflet for displaying maps.

- GeoDjango for geospatial data management in Django.

- GeoJSON for the transmission of geospatial data to the JS Leaflet library.

- Docker for the virtualization of development and production environments.

Both the database and Web servers have been deployed as docker instances. The points of difficulty are fed dynamically from an external Data Acquisition mobile application (see Sect.4), and effort scores of the itineraries are taken from the IBP index API.

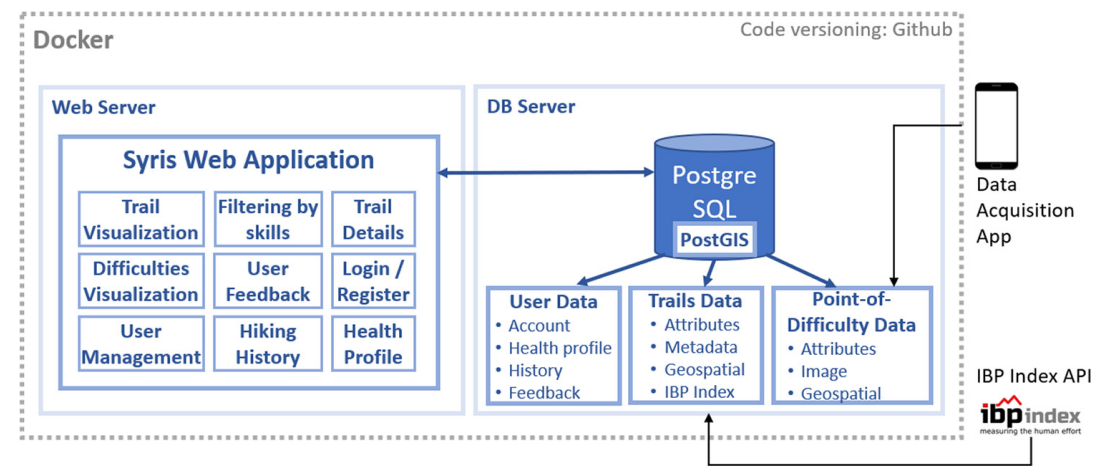

Fig. 2. Syris system architecture overview.

\section{Data Model}

To address the challenge of insufficient information about difficulties of pedestrian hiking trails, Syris incorporates a data model based on our previous research on semantic representations [4]. This data model considers the assessment of difficulties as a combination of three different dimensions, as developed by the classification methodology of the French Hiking Federation ${ }^{2}$ :

- Effort: this dimension is related to the physical energy required for a certain itinerary. The calculation of an indicator for this factor takes into account different parameters. For instance, the total distance, slopes, altitude, descent, and slope changes will directly affect the energy expenditure of a pedestrian

\footnotetext{
${ }^{2}$ Fédération Française de la Randonnée Pédestre (FFR) https://www.ffrandonnee.fr.
} 
track. In Syris, we use the IBP index ${ }^{3}$, a numerical scale for representing the human effort in hiking and biking tracks. The algorithm behind IBP takes as input the GPS coordinates of a trail and calculates an index based on the slope gradients, ascending and descending distances, altitude, etc.

- Technique: this dimension is associated with the motion/motricity required to overcome obstacles present in the track. Examples of technique-related difficulties include rocks that require specific skills to be overtaken, e.g., raising the leg to the knee or hip level, or even using the hands to overcome the obstacle. Given the lack of automatic calculations of an index for this dimension, experts usually perform the assessment on the in loco. Syris follows the scoring guidelines for the technique of the FFR, assessed by experts from the local Tourism Offices.

- Risk: this dimension entails a psychological difficulty related to situations to which the hiker is exposed and could lead to potential accidents or dangerous conditions. As with the technique, Syris requires the intervention of experts in the field to assess the risk level. This score is typically associated with the risk of falling (e.g., narrow passages, cliffs, abysses, unstable terrain) or losing control while climbing.

It is important to consider that a single hiking trail may be divided into different sections, with possibly very different difficulty characteristics. A pathway may start with a very easy sector in terms of risk and effort, while afterwards, there might be points of difficulty that require advanced skills to be crossed. In Syris, all major points of difficulty of a trail are reported and displayed. Moreover, the highest-ranking points are taken into account to have an overall characterization of the trail.

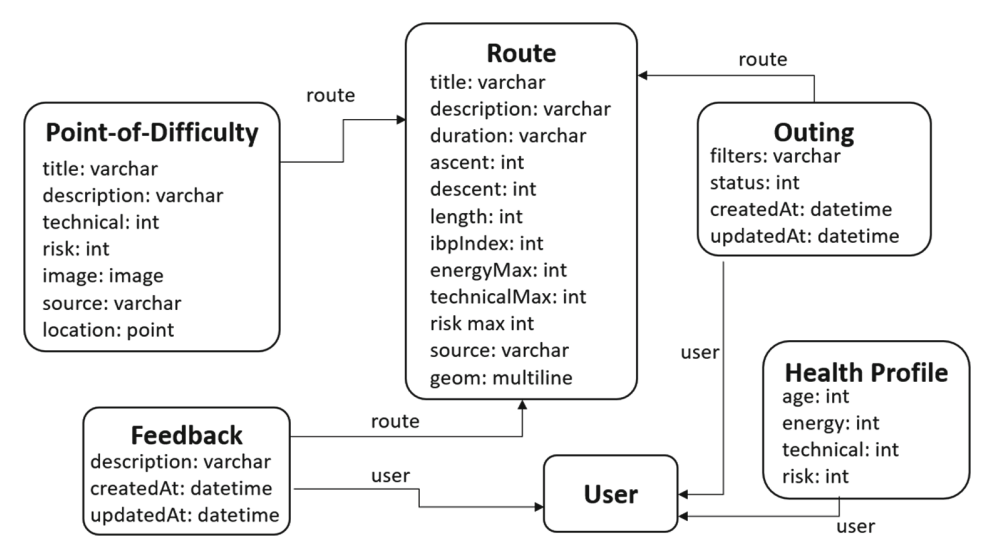

Fig. 3. Syris data model.

3 https://www.ibpindex.com. 
The data model of Syris, as depicted in Fig. 3, includes the following main elements:

- Routes: including the main information associated to an itinerary. Attributive data comprises the route title, short description, long description, duration, height difference, length, type (loop, round trip, traverse). It also includes route metadata regarding the risks, as described previously, i.e., IBP Index, energy, technical, risk. The route is also associated with a geometrical object, represented as a multi-line.

- Points of difficulty: includes attributes including title and description, as well as the risk and technical evaluation scores. It may also include an image of the point of difficulty, and the geometrical object, typically represented as a point in space.

- User information: which includes not only the user's basic information, but also the health profile (i.e., according to the Baecke questionnaire), and the risk/techniques scores. Any filtering and saved search are also stored, along with feedback provided about specific hiking routes.

\section{Data Acquisition}

Difficulty points are acquired in the field via a mobile application (Web or native) that allows the user to take a picture of the point of difficulty, obtain its geographic coordinates, and add a few attributes characterizing the type of difficulty. For the mobile application, we opted for using an existing mobile data acquisition platform: Appsheet ${ }^{4}$, which allows us to easily create a small mobile Web application with a form including the possibility to take pictures or to geo-locate the difficulty (Fig. 4). The data is saved and then imported into the Syris database through a Python script. Each time a point of difficulty image is imported into the Syris, it will be compressed, resized, while the latitude and longitude will be extracted, providing the location. Once the import is completed, recalculating the technical and psychological difficulties of the routes according to the newly imported point of difficulty is imperative. We have chosen to exclude points beyond a threshold distance from the route in the calculation of the difficulties score.

The data acquisition process has been validated by a set of volunteer betatesters who have hiked through the selected 70 routes of the region of Anniviers to collect difficulty points and populate our database. The points of difficulty collected have been validated by terrain experts, although it has been acknowledged that there is a need for a standardized procedure for such type of validation, potentially including the Swiss Council for Accident Prevention. Although the acquisition App is limited to the collection of points of difficulty, it has been evidenced that its usage could be extended in order to provide data quality and validation features. Following a citizen-science approach, a collaborative methodology can be put in place in order to allow users to contribute difficulty and risk data according to an established protocol.

\footnotetext{
4 https://www.appsheet.com/.
} 


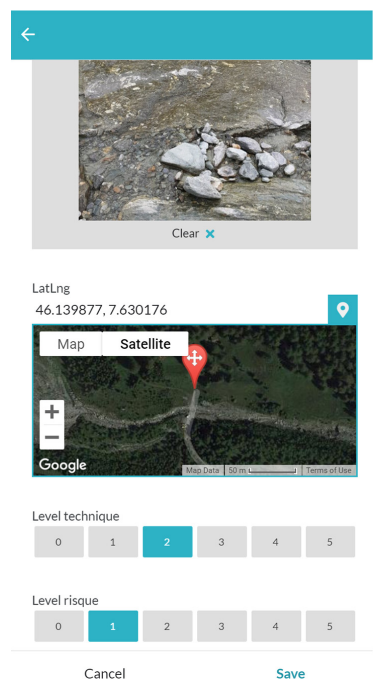

Fig. 4. Syris acsuition app based on appsheet.

\section{Trails Visualization}

Hiking itineraries are geo-located and displayed on a Leaflet map in order to allow the user to explore and visualize them. Depending on the required level of detail, different visualization options are available, i.e., display all routes on a map with an icon that points to the route starting point; or display the route and its difficulty points.

By default, the map is centered on Sierre with an undefined radius. These two filters (center and radius) are not modifiable. At this stage, we decided to display only the routes of Anniviers. Although initially we had imported all the itineraries from Valrando, it was evidenced that several attributes were missing. Thus, for the sake of clarity, we decided to take only the itineraries from Annivers Tourisme. The itineraries are clustered according to the zoom level, and coloured according to the difficulty levels.

A color scheme has been established to denote physical difficulty: Easy $\rightarrow$ Green; Easy enough $\rightarrow$ Blue; Not very difficult $\rightarrow$ Orange; Quite difficult $\rightarrow$ Red; Difficult $\rightarrow$ Black. It is possible to change the color assignment according to the technical or psychological difficulty by clicking on the wheel configuration icon at the bottom of the map. The icons are clickable and display a pop-up with route information and the link to display the route. By default, the map type is OpenStreetMap, but it is possible to change it, for instance, using SwissTopo maps (with their agreement, free for research projects below a certain quantity of maps displayed). The routes displayed on the map are also listed below the map. The list updates automatically after each Zoom or Drag (Fig. 5).

The physical difficulty of a route is calculated from its IBP Index. We performed the calculation (via API) for all routes and stored the information in the 


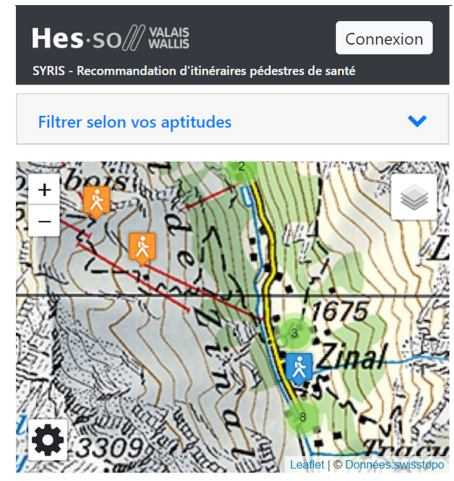

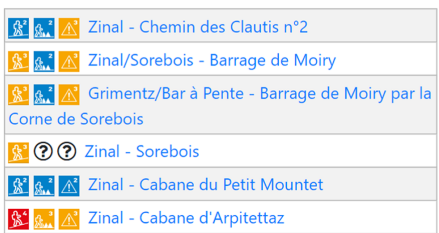

Zinal/Sorebois - Barrage de Moiry

\section{sin}

$\rightarrow 5.9 \mathrm{~km} \quad \triangle 423 \mathrm{~m} \quad-601 \mathrm{~m} \quad \bigcirc 02: 30 \mathrm{hr}$

Après avoir rejoint Sorebois grâce au téléphérique, cette belle randonnée vous conduira près de la Corne de Sorebois avant d'entreprendre la descente jusqu'au barrage de Moiry.

Afficher les détails

Grimentz/Barrage de Moiry - Haut tour du lac par le Chemin 2500

\section{迹 4}

$\rightarrow 12.8 \mathrm{~km} \quad \triangle 567 \mathrm{~m} \quad \rightarrow 567 \mathrm{~m} \quad \bigcirc 04: 45 \mathrm{hr}$

A 2500 mètres découvrez un chemin enchanteur avec une vue magique sur le lac.

Afficher les détails

Zinal - Chemin des Clautis $\mathrm{n}^{\circ} 2$

\section{$\mathrm{S}^{2} \mathrm{Bn}^{2}$}

$\rightarrow 2.7 \mathrm{~km} \quad-128 \mathrm{~m} \quad-136 \mathrm{~m} \quad \odot 01: 00 \mathrm{hr}$

Chemin de randonnée qui nous fait découvrir le fond de la vallée par forêt. Facile, il peut être effectué avec de jeunes enfants.

Fig. 5. Syris: details on hiking trails and list of trails.

database. On the other hand, the technical and psychological difficulties depend on the difficulty points of the itinerary. If no POD is recorded, the difficulty cannot be calculated, and an icon with a question mark is displayed.

\section{Filtering and Recommendation}

\begin{tabular}{|c|c|c|}
\hline \multicolumn{2}{|l|}{ Filtrer selon vos aptitudes } & $\checkmark$ \\
\hline \multicolumn{3}{|l|}{$\square$ Je suis membre d'un groupe } \\
\hline $\begin{array}{l}\text { Ma condition physique ou celle de } \\
\text { mon groupe* } \mathbf{O}\end{array}$ & $\begin{array}{l}\text { Ma capacité motrice ou celle de } \\
\text { mon groupe* }\end{array}$ & $\begin{array}{l}\text { Mon aptitude ou celle de mon } \\
\text { groupe à gérer le risque ou la } \\
\text { peur du vide* } \text { vi }^{*}\end{array}$ \\
\hline 1 Facile & 1 Facile & $1 \unlhd$ Facile \\
\hline - 2 成 Assez facile & 2 Assez facile & $2 \Delta$ Assez facile \\
\hline 3 Peu difficile & - 3 Peu difficile & - $3 \triangle$ Peu difficile \\
\hline 4 Assez difficile & 4 Assez difficile & $4 \triangle^{\top}$ Assez difficile \\
\hline 5 Difficile & 5 Difficile & 5 Difficile \\
\hline \multicolumn{3}{|c|}{ *nspiré du guide de cotation de la Fédération Française de Randonnée } \\
\hline & & Filtrer \\
\hline
\end{tabular}

Fig. 6. Syris: Filtering criteria for effort, risk and technique.

The terminology, icons, and descriptions of the skill types are based on the rating system of the Fédération Française de Randonnée. The main filters based on the user ability are (as related to the data model in Sect.3): Energy (E): Fitness; 
Technique (T): Motor capacity; Risk (R): Ability to manage risk. Fear of heights has been added to this category. On the route index page, logged-in or logged-out users can directly define their skills and filter routes accordingly Fig. 6.

The filters linked to the group are currently only informative, and the idea is to integrate them on the route recommendation. Such filters are saved in the database when creating an output. The user can click on the question marks to display each ability's information in a modal window.

To filter trails according to the user fitness level, we have used the Baecke questionnaire [1]. It contains 23 questions and returns a score between 0 and 15 , which allow the user to determine his level of fitness. The complete form adapted to the Syris web application is available online ${ }^{5}$ as seen in Fig. 7. For logged users, a filtering button is activated, which allows the transfer of the defined filters and saves them in the Health Profile area of the user. The age is purely informative at the moment but could be useful to refine the health profile and, thus, the itinerary recommendation.

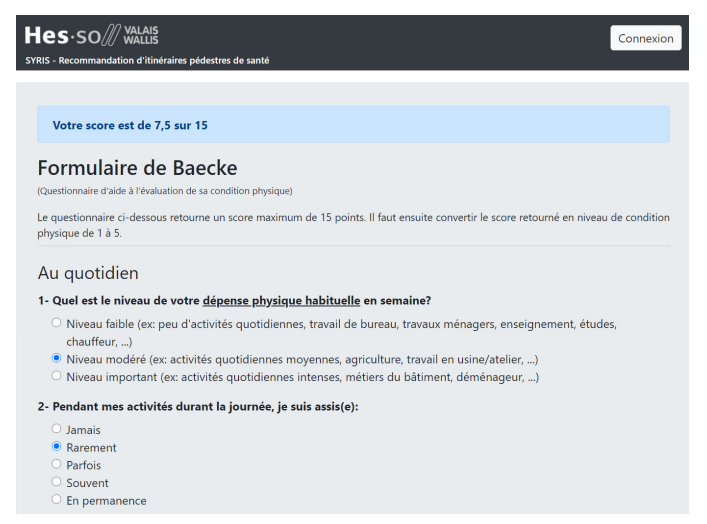

Fig. 7. Excerpt of the adapted Baecke questionnaire in Syris.

\section{Deployment}

The system is fully virtualized in Docker containers. The database is stored in a Docker volume, which allows the database server container to be stopped and restarted without losing the data stored in it. In production, the Web application's source code is copied directly into the custom Docker image that serves the Web server, unlike development where the source code is mounted on a volume to allow on-the-fly code modification and automatic restart of the Web server. The source code is stored in a GitHub directory. The system shares the Docker server with other solutions. They are managed by Traefik, which defines the port and URL alias and secures the data exchange (SSL).

5 https://syris.iigweb.hevs.ch/fr/profile/baecke. 


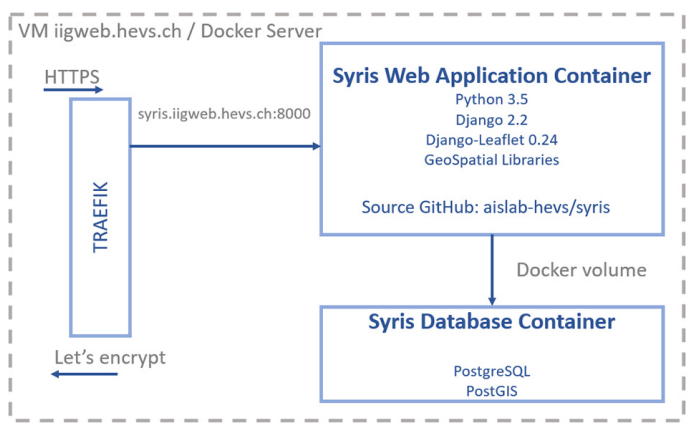

Fig. 8. Deployment architecture.

\section{Related Work}

The extensive affirmation of hiking among the most practiced outdoor activities has stimulated the creation of heterogeneous segments to satisfy the demand of a population spanning from beginners/people with limited mobility to professional athletes. Such a trend encouraged more investments in maintaining and promoting hiking sites, which in turn produced a remarkable return of interest [19,20]. In turn, the need for improving existing guidelines and their accessibility has attracted the attention of health institutions and associations $[8,11,14]$, who promoted initiatives to raise awareness about hiking trail difficulties [12]. Studies assessing difficulty in terms of energy expenditure [10], hikers' preparedness [15], and collaborative annotation of tourism objects ${ }^{6}$ can be considere pioneers. More recent contributions span from preference-based recommendations for groups of users [7] to more technological ones employing recommender chatbots [16].

However, providing suggestions for hiking trails has only been addressed partially. For example, some recommendation systems rely on hiking time estimation $[2,18]$ or on questionnaires to estimate the users' physical condition [5]. On the one hand, although some studies introduced elements relevant for evaluating track difficulties, all of them overlooked several factors included in Syris. On the other hand, several standards for representation and modeling of tourism and travel concepts arose. For example, Open Travel Schema developed by the Open Travel Alliance (OTA $)^{7}$ is a standard model for travel objects. However, it mostly focuses on booking information and neglects to current ontology modeling standards. The WTO (World Tourism Organization) [17] developed the Thesaurus on Tourism and Leisure Activities, used mainly for indexing concepts in the tourism realm. Similarly, a set of standards, including different messaging and tourism agent specifications, has been provided by the Travel Technology Initiative ${ }^{8}$.

\footnotetext{
6 https://www.apidae-tourisme.com/.

7 https://opentravel.org.

8 https://www.tti.org/.
} 
Solely focusing on booking operations and availability, and less on outdoor activities, such standards can guide the integration of tourism information. Nevertheless, the more significant limitation is the lack of data description models for pedestrian roads and the different aspects tackled in Syris (e.g., description and specification of difficulty types).

Although neglecting the modeling of hiking difficulty types, many interesting systems/projects focusing on outdoor activities are worth mentioning. In Austria, the local tourism office (Vorarlberg ${ }^{9}$ ) maintains an online database of hiking trails. The Swiss canton of Valais delegated the management of official hiking trails to Valrando ${ }^{10}$. Similarly, SuisseMobile ${ }^{11}$ provides online apps mapping pedestrian trails and respective technical information. Moreover, regional tourism offices offer complementary services with more detailed and accurate information, sometimes exploiting third party companies such as Outdooractive $^{12}$ or Snukr ${ }^{13}$. To collect and maintain up to date information about hiking trails are expensive and robots/humans-intense activities [6,13]. Nevertheless, this detailed information is crucial to provides hikers with crucial indications about the trails they are willing to undertake.

If the potential hikers have physical limitation(s), the complexity and heterogeneity of the pathways characterization might escalate, thus requiring proper models to handle factors such as fear of heights, climbing constraints, reduced mobility, walking aids, or terrain preferences, etc.

\section{Discussion}

This paper presents a novel system for assessing difficulty points in hiking trails, considering different dimensions related to effort, technique and risk. The implementation of this data model opens the door for providing recommendations based on the matching of the health profile of a user with the characteristics of available routes. The Syris prototype includes several important steps in the data life-cycle of pedestrian and mountain routes, from data modelling, acquisition, storage, exploitation, and validation. In this regard, it has the potential for empowering different types of users, according to their needs. For example, regional tourist offices and local development authorities can use it as a basis for tailored recommendations for tourists, reaching segments of the population such as older adults and people with disabilities. Health professionals can also use Syris for helping patients to adhere to physical activities that increase their quality of life. For mountain guides, it can help as a tool for assessing and validating difficulty points, and choosing the best itinerary for a group of customers. Moreover, Syris can be used as an instrument of prevention, with the indirect

\footnotetext{
9 https://www.vorarlberg.travel.

10 https://www.valrando.ch/.

11 https://www.schweizmobil.ch.

12 https://www.outdooractive.com.

13 https://www.snukr.com.
} 
target of decreasing the number of accidents thanks to a better understanding of risks and difficulties.

Although Syris was conceived fundamentally for the assessment of difficulties in pedestrian routes, it is easy to see that the concept can be expanded towards a Citizen Science approach for acquiring, managing and validating outdoor activity data. This concept may extend also to other sports such as mountain biking or even skiing, although with additional constraints. The data acquisition approach, which is currently implemented simply for difficulty points, can also be expanded to gather other types of relevant information, e.g., pollution indicators, weather-dependent risks, or difficulties according to age. Moreover, we see the potential of using gamification techniques in order to provide incentives and motivation cues to potential contributors to the platform. This can also be applied in order to teach users to assess risks and difficulties, through game/example based training scenarios. Furthermore, it is clear to see that a full evaluation of this approach will require considering not only the hiking experience aspects, but also the usability/visualization aspects. In order to do so we expect to expand the database beyond the itineraries of Val d'Anniviers, in order to have a larger and more heterogeneous set of scenarios and user base.

\section{Conclusions and Future Work}

This paper introduced Syris, a system for managing difficulty and risk data of pedestrian routes. The system was conceived to manage the entire data life-cycle for hiking trails, from data acquisition, to storage and exploitation. The Syris data model considers different risk and difficulty dimensions, which can also be used to provide recommendations according to a user profile. The system has been implemented, deployed, and validated using real hiking trail data from the Val d'Annivers valley in Switzerland.

In the future, we will focus on specializing recommendations, by taking into account other factors, such as weather-related variables, or by using other alternative fitness assessment instruments other than Baecke's questionnaire. Once a large amount of user data is collected, alternative recommendation mechanisms can be explored, focusing on the usage of feedback, as well as profile learning. We will also study the assessment and perception of risks not only from individuals but also for groups of users, as well as identifying potential clusters of users with similar characteristics. Enabling group recommendations would entail changing the way of assessing physical and technical skills, as well as applying adequate matching strategies to existing itineraries. Finally, we will analyze the potential impact of the Syris platform in certain industry sectors such as insurances, outdoor activity providers, and prevention organizations, which may benefit from the results of this initiative.

Acknowledgements. Supported by the HES-SO RCSO ISNet grant Syris. Thanks to Joan Casares and the IBP Index team, and to Anniviers Tourisme for their support. 


\section{References}

1. Baecke JA, Burema J, Frijters JE (1982) A short questionnaire for the measurement of habitual physical activity in epidemiological studies. Am J Clin Nutr 36(5):936-942

2. Boerger M (2014) Hiking suggestions and planner. US Patent 8,688,374, 1 Apr 2014

3. Boller F, Hunziker M, Conedera M, Elsasser H, Krebs P (2010) Fascinating remoteness: the dilemma of hiking tourism development in peripheral mountain areas. $\mathrm{Mt}$ Res Dev 30(4):320-332

4. Calbimonte JP, Martin S, Calvaresi D, Zappelaz N, Cotting A (2020) Semantic data models for hiking trail difficulty assessment. In: Neidhardt J, Wörndl W (eds) Information and communication technologies in tourism 2020, pp 295-306. Springer, Cham

5. Calbimonte JP, Zappellaz N, Hébert E, Simon M, Délétroz N, Hilfiker R, Cotting A (2018) SanTour: towards personalized recommendation of hiking trails to health profiles. In: Pautasso C, Sánchez-Figueroa F, Systä K, Murillo Rodríguez J (eds) Current trends in web engineering, pp 238-250. Springer, Cham

6. Carvalhinho L, Rosa P, Gomes F (2015) Hiking trails evaluation in the natural park of serras de aire e candeeiros, Portugal. Eur J Tour Hosp Recreat 6(2):139-156

7. Delic A, Neidhardt J (2017) A comprehensive approach to group recommendations in the travel and tourism domain. In: Adjunct publication of the 25th conference on user modeling, adaptation and personalization, pp 11-16. ACM

8. Haskell WL, Lee IM, Pate RR, Powell KE, Blair SN, Franklin BA, Macera CA, Heath GW, Thompson PD, Bauman A (2007) Physical activity and public health: updated recommendation for adults from the American college of sports medicine and the American heart association. Circulation 116(9):1081

9. Heberlein TA, Fredman P, Vuorio T (2002) Current tourism patterns in the Swedish mountain region. Mt Res Dev 22(2):142-150

10. Hugo ML (1999) Energy equivalent as a measure of the difficulty rating of hiking trails. Tour Geogr 1(3):358-373

11. Jackson J, Murphy P (2002) Tourism destinations as clusters: analytical experiences from the new world. Tour Hosp Res 4(1):36-52

12. Kortenkamp KV, Moore CF, Sheridan DP, Ahrens ES (2017) No hiking beyond this point! hiking risk prevention recommendations in peer-reviewed literature. $\mathrm{J}$ Outdoor Recreat Tour 20:67-76

13. Lee SY, Du C, Chen Z, Wu H, Guan K, Liu Y, Cui Y, Li W, Fan Q, Liao W (2020) Assessing safety and suitability of old trails for hiking using ground and drone surveys. ISPRS Int J Geo-Inf 9(4):221

14. Lloyd-Jones D, Adams R, Brown T et al (2010) Health benefits of hiking. Circulation 121:e1-e170

15. Mason RC, Suner S, Williams KA (2013) An analysis of hiker preparedness: a survey of hiker habits in new hampshire. Wilderness Environ Med 24(3):221-227

16. Nguyen TN, Ricci F (2017) A chat-based group recommender system for tourism. In: Schegg R, Stangl B (eds) Information and communication technologies in tourism 2017, pp 17-30. Springer, Cham

17. Organization WT (2001) Thesaurus on Tourism and Leisure Activities. UNWTO

18. Pitman A, Zanker M, Gamper J, Andritsos P (2012) Individualized hiking time estimation. In: 2012 23rd international workshop on database and expert systems applications, pp 101-105. IEEE 
19. Scarpa R, Thiene M, Tempesta T (2007) Latent class count models of total visitation demand: days out hiking in the eastern alps. Environ Resour Econ 38(4):447460

20. Thiene M, Scarpa R (2008) Hiking in the alps: exploring substitution patterns of hiking destinations. Tour Econ 14(2):263-282

Open Access This chapter is licensed under the terms of the Creative Commons Attribution 4.0 International License (http://creativecommons.org/licenses/by/4.0/), which permits use, sharing, adaptation, distribution and reproduction in any medium or format, as long as you give appropriate credit to the original author(s) and the source, provide a link to the Creative Commons license and indicate if changes were made.

The images or other third party material in this chapter are included in the chapter's Creative Commons license, unless indicated otherwise in a credit line to the material. If material is not included in the chapter's Creative Commons license and your intended use is not permitted by statutory regulation or exceeds the permitted use, you will need to obtain permission directly from the copyright holder.

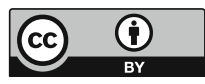

